\title{
The Research of the Library Services Based on Internet of Things
}

\author{
Jianning Qin \\ Library, Jinan University, Guangzhou 510000, China. \\ tqin@jnu.edu.cn
}

Keywords: Library services; Internet of Things; Information technologies; Services.

\begin{abstract}
The purpose of this paper is to study the possible scope and usage forms of Internet of Things technology in library services. Based on the analysis of the subject literature, the main areas of IoT applications in commercial institutions were ascertained, and then an analysis of Library and Information Science English-language literature from 2010 to 2017 was made in order to draw an outline of modern library service. The scope of activities of commercial and non-commercial institutions was compared to determine whether areas in which commercial entities using or planning to use IoT could also bring inspiration to libraries. In this way, a theoretical model of IoT use in library activities was developed. The research indicates that IoT technology may have the possibility to be used in library services and other activities, similar to how it is implemented in the commercial sector. The use of IoT in libraries is a new issue that has not been studied much yet. In recent years, at the international conference, the possibility of using this technology to meet the needs of libraries has been raised and become a subject of interest to librarian associations. It proves that this topic is important to practitioners. However, it's difficult to find any scientific comprehensive research on this subject.
\end{abstract}

\section{Introduction}

Currently the development of information and communication technology is very fast, and the result of this phenomenon affects the library. After a period of intensive computerization of libraries, the beginning of the 21 st century has been a time of great interest in social media issues and mobile technology, but libraries are constantly faced with new challenges. New technologies such as augmented reality, wearable computing and 3D printing are gradually related to library services, forcing continuous development and offering customized service, in order to adapt to evolving customer habits. Internet of Things (IoT) is one of the most interesting concepts in recent years and it could potentially be a big challenge for libraries.

The subject of this paper is the potential of IoT technology for libraries. The goal is to determine the possible scope and forms of the use this technology in public and academic library services. The specific aims are as follows:

Define the form of modern library services;

Determine the possibility of IoT for the improvement of library services;

Describe examples of IoT applications in libraries;

Make prospects for the use of IoT in libraries.

\section{Research Methods}

The implemented analysis consists of several stages. In the first stage, based on the analysis of the subject literature and reports provided by major companies in the field, the main types of IoT applications developed by commercial companies were identified. Therefore, more than 30 of the most relevant abstracts or full texts of English-language papers published in 2010-2017 were analyzed. In the second stage, an analysis of LIS English-language literature from 2010 to 2017 was conducted in order to make an outline of modern library services. More than 30 articles relating most to the characteristics and forms of modern library services were analyzed. After that, the activities of commercial and non-commercial institutions were compared. The purpose was to determine whether 
the area in which commercial institutions using or planning to use IoT could give inspirations to libraries as well. Therefore, a theoretical model for the use of IoT in library activities was developed. In the final stage, both subject literature and web resources were searched to find examples of actual attempts to implement the IoT in libraries. Finally, the conclusion of the future outlook on the use of IoT in the library was formulated. The developed model relates to the potential use of IoT in library services.

\section{About Internet of Things}

\subsection{Description of IoT.}

Internet of things is a concept that has been widely described since the late 1990s. Various aspects of this issue are emphasized in many definitions. According to L. Atmore, A. I era and G. Moabite, it can be described as a "novel paradigm that is rapidly gaining ground in the scenario of modern wireless telecommunications" [2]. These authors explained that "the basic idea of this concept is the pervasive presence around us of a variety of things or objects such as Radio-Frequency Identification RFID) tags, sensors, actuators, mobile phones, etc. which through unique addressing schemes, are able to interact with each other and cooperate with their neighbors to reach common goals" [2]. According to another similar definition "IoT refers to the networked interconnection of everyday objects, which are often equipped with ubiquitous intelligence" [6]. The IoT is also considered to be a part of the so-called Future Internet, defined as a "dynamic global network infrastructure with self-configuring capabilities based on standard and interoperable communication protocols where physical and virtual things have identities, physical attributes, virtual personalities, use intelligent interfaces, and are seamlessly integrated into the information network" [10].

In summary, it appears that the main idea of the IoT is based on the assumption that everyday objects equipped with appropriate sensors and network access can communicate to fulfill certain tasks. Internet of Things is the technology of the future, therefore, its advantage and disadvantage must be thoroughly recognized because it will become more ubiquitous.

\subsection{IoT in Commercial Services.}

There are some similarities between the activities implemented by commercial and non-commercial institutions in many years. The LIS area is a good example of this statement. The main task of the library - to mediate in communication - is carried out by lots of commercial entities from various industries, often in very interesting and innovative ways. Commercial institutions, defined here as entities whose primary goal is to pursue profits by satisfying consumers' demands, often have sufficient financial and technical resources that enable them to deploy new solutions faster than non-commercial institutions. Therefore, if conditions allowed, it's worth studying the idea and experience of commercial institutions, which may be beneficial to the non-profit institutions.

The analysis of subject literature was focused on the implementation of the IoT in business, mainly in industries such as communications, management, consulting transport and logistics, and several key application areas of this technology can be distinguished. Of course, the diversity of IoT usage ideas is great, but the goal is not to describe it in detail, only to draw out some general trends. The summary of this analysis is shown in Fig 1.

The analysis showed that commercial institutions use the IoT to share contextual information about products and services. One example may be the trend of sending so-called push notifications that display contextual information about products and services on a mobile device, e.g. when passing or staying at a specific location in a mall. This is still a concept compared to widely used solutions, however, push notifications have become a part of shopping experiences of many smartphone users. Similar solutions are also used in marketing as a part of a participative concept. 


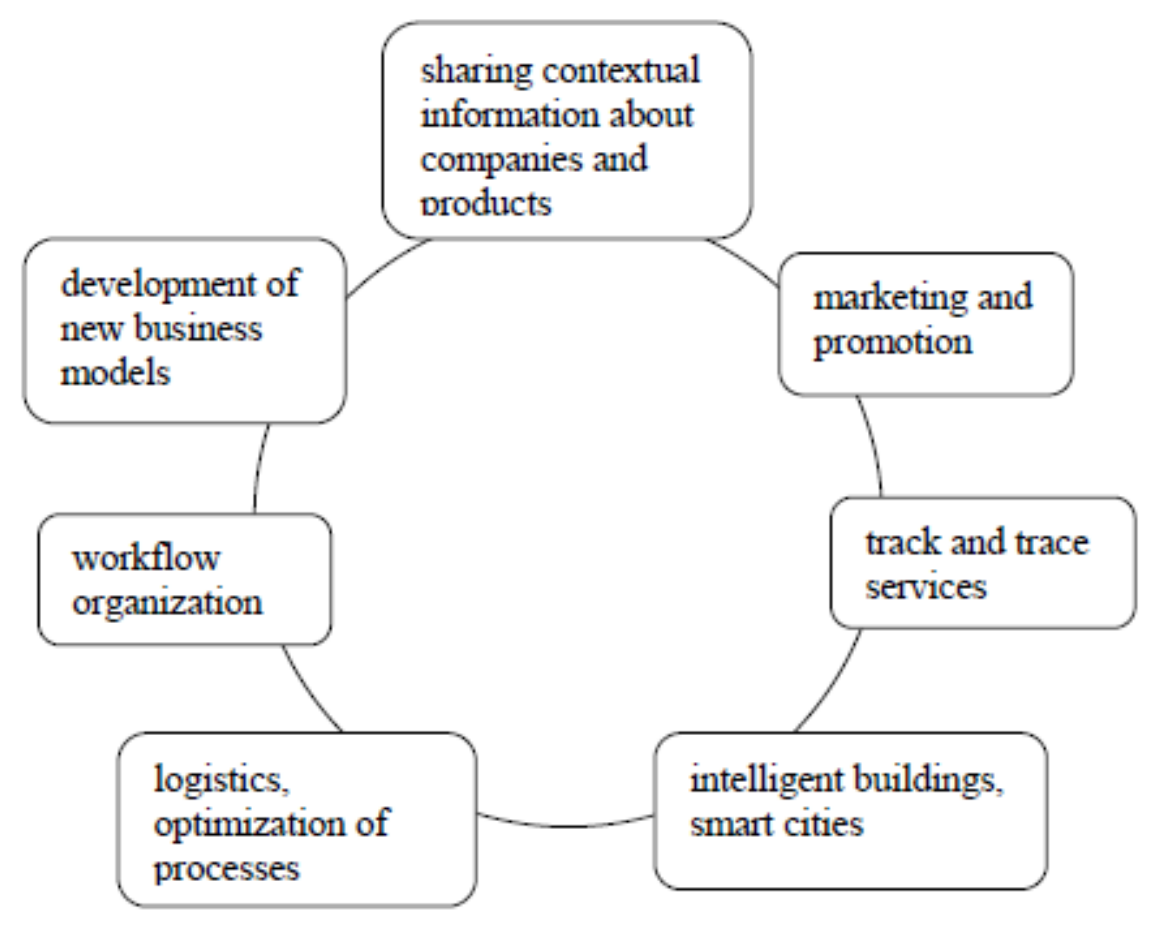

Fig.1 The main areas of IoT use in the commercial sector

The IoT is frequently used in various environments related to improved organizational, management and planning. This proof is the use of IoT technologies in logistics tracking services such as airports, transportation companies and transportation. The possibilities offered by communication between IoT objects make it easier for many industries to manage standard processes. On a large scale, IoT solutions are used in so-called smart buildings and smart cities. The idea of a smart city is based on the assumption that the device can personalize the user's environment based on the information sent by the mobile device, providing many opportunities that are still difficult to predict. Today, many processes implemented in buildings are already automated.

Today, many processes implemented in buildings have been automated. The management of air conditioning, temperature or alarm systems is not a problem for modern buildings, but many Internet of Things commentators predict that not only smart but also truly intelligent buildings have the characteristics of artificial intelligence and the ability to make independent and accurate decisions, but this is still in the future.

The IoT is widely used in logistics, processes and workflow organizations. The use of this technology can improve the organizational structure on the individual and enterprise level. The IoT allows real-time monitoring and optimization of processes, whether they are related to production, services, trade, warehousing, transportation, or other business activities. In the subject literature, IoT has also been widely reported to create new business models. It is believed that the IoT can provide technical and conceptual conditions for developing new ideas of providing products and services to customers. According to some authors, the use of IoT technology is well suited to the global trend of providing all goods as a service. The full scope of the IoT for business model creation is not yet clear, but the existing business potential IoT application model is promising.

\section{Modern Libraries' Services}

Talking of the specifics of modern library services, the core of library services is still essentially the mediation of access to information, despite passing time and technological changes. The main area of library services is still the access to both traditional and online collections been provided in the subject literature. The area of advisory services is equally important as the consultation. Library services are currently available in various forms and provide tools such as chat, e-mail, social media, mobile applications and others. But when talking about their basic nature, it seems that the core of 
library services can be divided into groups. Firstly, sharing information in the form of dates, names, facts and so on. Secondly, providing catalog and bibliographic information which help users with navigating through library resources and finding out relevant sources of information. Thirdly, providing access to traditional and online collections in terms of lending materials and making tem available on-site or remotely. As mentioned before, in the modern library service model, providing access to information and traditional electronic resources is often integrated into a complex process and hopes to find a comprehensive solution for user's problem. Another aspect of the library service model is the provision of space and equipment, such as library rooms, computers, scanners, information search tools, etc. Finally, there is complex consulting and training on the use of the library, its contents and about information retrieval in general, In the modern world, libraries play an important role in the field of the education competences and information/media literacy. Providing education in the field of improving the quality of information is one of the most important library services.

\section{The IoT in Library Services}

\subsection{A Theoretical Model.}

In this section, the behavior of a theoretical model is designed and described to create a networking application library service with problems. Things universally apply and can be widely used regardless of the nature of the business profile of the company or organization. The idea is based on the following assumption. To validate this hypothesis, the IoT use in various commercial areas were analyzed to select the most common fields of use, which were then divided into services and other activities. The results of this analysis are compared with the list of major services and other activities provided by the libraries to seek the commonalities in terms of functions performed by commercial enterprises and libraries. The author believes that if the functions/activities of various industries and libraries are similar and commercial enterprises use the IoT, then libraries are theoretically feasible. The results of this comparison are shown in Tables 1 and 2.

The first comparison of services shows that the IoT may be used in libraries to provide access to traditional and online collections and providing factual and directory information, just like in commercial sector. For example, this technology can make it easier for librarians and users to find physical objects and browse virtual resources in the library. It could also be used to provide contextual hints and information about resources relevant to the current user's interests. The IoT could also be potentially useful in other areas of library services, such as consulting and training. In this context, the IoT could be used to download up-to-date information about users from their mobile devices, such as their mood, daily schedules, etc., and personalize training courses based on this data. The IoT could also be used to indicate the availability of devices and resources to prevent users from being frustrated by lack of space in the reading room or the unavailability of workstations.

The comparison of other commercial IoT uses against other types of library activities also revealed interesting possibilities. It seems taht although the IoT had the potential to be frequently used in marketing and promotion, its usefulness is not limited to this area. It could also be used in process optimization, library workflow organization, and the development of innovative business models that make libraries more fun for users and other stakeholders. Using innovative IoT-based marketing techniques to promote libraries and organizational activities can help to establish libraries as modern institutions that follow current trends. This technology could also be used to simplify the internal library process. For example, collecting, describing and analyzing resources, intelligent building technology and appropriate resource storage.

In summary, the main potential area of the IoT use in library services are providing directory information and providing access to traditional and online collections. The IoT also has potential for consulting and training, tracking and tracking services, and information sharing (Fig 2). 
Table 1. Comparison of IoT's fields of use in services of commercial companies with the range of modern libraries' services

\begin{tabular}{|c|c|c|}
\hline & $\begin{array}{l}\text { Providing contextual information about } \\
\text { companies and products }\end{array}$ & $\begin{array}{l}\text { Track and trace } \\
\text { services }\end{array}$ \\
\hline $\begin{array}{l}\text { Providing access to traditional and } \\
\text { online collections }\end{array}$ & ( & 1 \\
\hline Consulting, training & 1 & 0 \\
\hline Sharing factual information & 1 & 0 \\
\hline Providing directory information & 1 & 1 \\
\hline $\begin{array}{c}\text { Providing access to space and } \\
\text { equipment }\end{array}$ & 0 & 1 \\
\hline
\end{tabular}

Notes: 1 - there is a match; 0 - there is no match

Table 2. Comparison of other fields of IoT use in commercial companies with non-service library activities

\begin{tabular}{|c|c|c|c|c|c|}
\hline & $\begin{array}{l}\text { Marketing } \\
\text { and } \\
\text { promotion }\end{array}$ & $\begin{array}{l}\text { Logistics, } \\
\text { optimization of } \\
\text { processes }\end{array}$ & $\begin{array}{c}\text { Workflow } \\
\text { organization }\end{array}$ & $\begin{array}{c}\text { Development of } \\
\text { new business } \\
\text { models }\end{array}$ & $\begin{array}{c}\text { Constructing } \\
\text { smart } \\
\text { buildings }\end{array}$ \\
\hline Gathering & 0 & 1 & 1 & 0 & 0 \\
\hline Description & 0 & 1 & 1 & 0 & 0 \\
\hline Storage & 0 & 1 & 1 & 0 & 1 \\
\hline $\begin{array}{l}\text { Analysis and } \\
\text { selection } \\
\text { of collection }\end{array}$ & 0 & 1 & 1 & 0 & 0 \\
\hline $\begin{array}{l}\text { Marketing } \\
\text { and } \\
\text { promotion }\end{array}$ & 1 & 1 & 1 & 1 & 0 \\
\hline $\begin{array}{c}\text { Beyond } \\
\text { services offer }\end{array}$ & 1 & 1 & 1 & 1 & 0 \\
\hline
\end{tabular}

Notes: 1 - match exists; 0 - no match

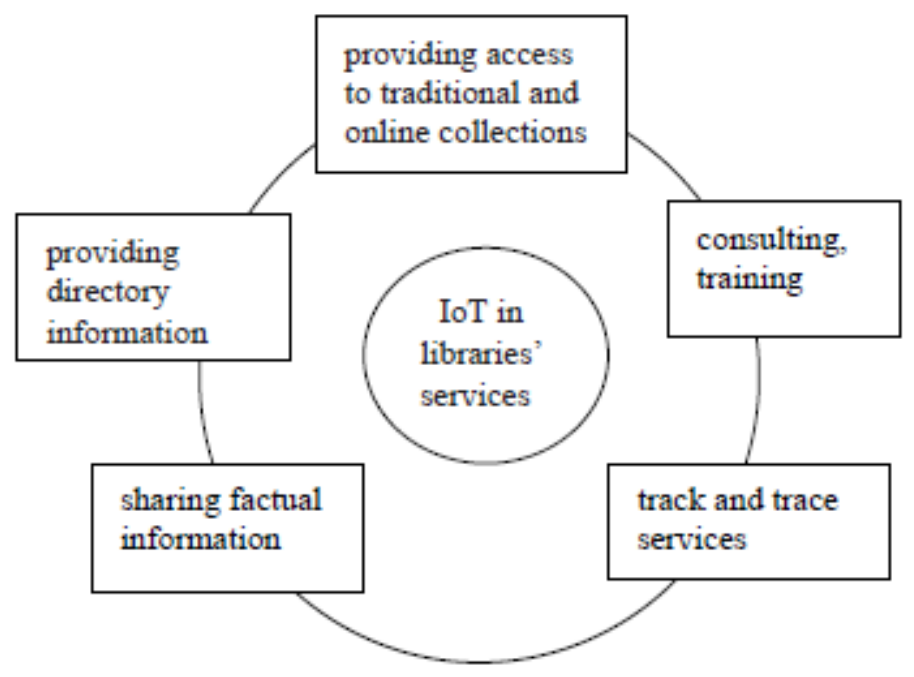

Fig 2. The main areas of potential IoT use in library services

Regarding the use of IoT in other library activities, the most promising areas seem to be marketing, promotion, storage, cultural events and events. IoT can also be used to collect collections, descriptions, analysis, and collection selections (Fig 3). 
Overall, it seems that the IoT can theoretically be successfully used in almost every area of library work, including both services and other activities.

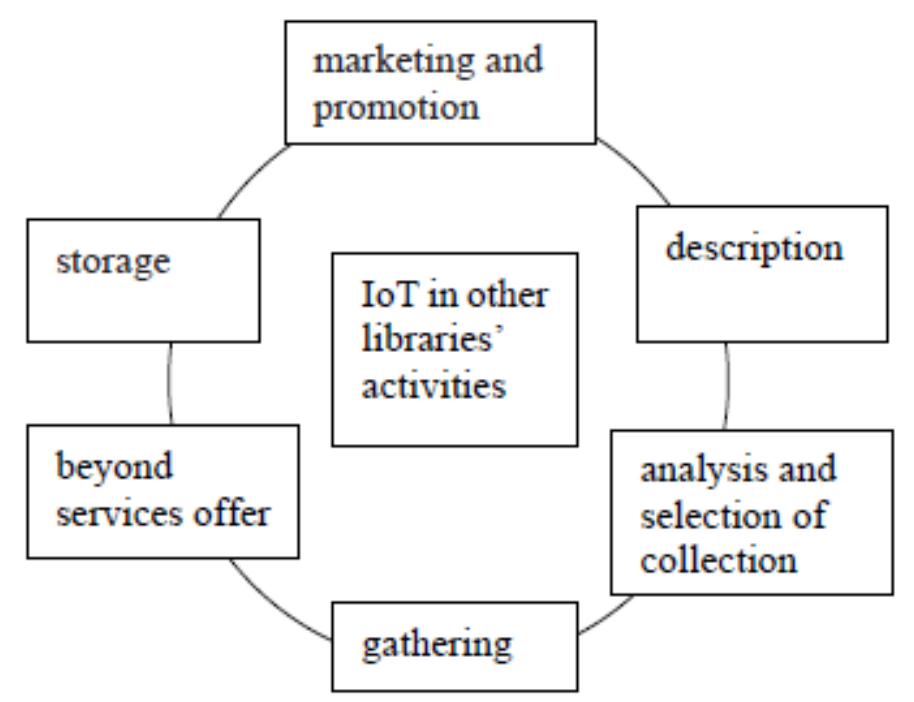

Fig 3. The main areas of potential IoT use in other library activities

\subsection{Iot in Library: Implementation Example.}

There are not many existing descriptions of IoT use in libraries, however literature analysis and network resources revealed some interesting initiatives.

The first is the BluuBeam application implemented by the Orlando Public Library. This application is based on the beacon technology commonly used in extended reality programs. BluuBeam sends location triggers to mobile devices to help users search for resources and use their context queue to expand interest. Product features are conceptual simplicity, easy interpretation to users, and its high utility of context search. The BluuBeam technology used in the Orlando Public Library, according to its founder, is also used in about 30 other US libraries. Unfortunately, other examples using BluuBeam in the library are not well documented [22].

Caper Technologies has a competing idea of using the library's Internet. The company offers solutions that enable integration of mobile applications with existing libraries system. Applications can be tailored to the individual needs of the library Extensive possibilities: Users can receive notifications about the status of their account and can notify library events, search directories, and receive personalization [27].

Librarians have status notifications related to current concerns. According to one of Coria's co-founder, this application is widely used in over 100 libraries. Examples are Somerset County Library and Half Hollow Hills Community Library.

\section{Conclusion}

Despite several successful initiatives, the IoT in libraries is still more a concept than reality. It remains to be seen what will happen in the future. This suggests that although the predicted IoT boom has yet to come, the first signs of this technology are already clearly visible. It seems logical that in this context, libraries will include IoT in their service range to follow global trends and better meet users' needs.

Based on observation of the commercial sector, this paper presents one vision of the potential of IoT for libraries and attempts to identify areas of library activities in which this technology could perform well. Analysis showed that some commercial activities overlap with library services. Therefore, libraries can theoretically use the IoT in a similar way to commercial institutions. The obstacles to the use of IoT in the library services are, of course, financial and organizational, but the potential is clearly visible. In the area of library services, the greatest potential of IoT technology can 
be seen in process of providing access to traditional and online collections and providing directory information. IoT technology can also be useful for sharing information, conducting consulting or training, and providing access to spaces and equipment.

IoT technology may also be useful in other non-service library activities such as gathering, description, storage, analysis and selection of collections, marketing and promotion, and event organization.

Among potential areas of IoT use, the following content is listed: tracking books; organizing self-guided tours; making exhibits in special collections more interesting; providing options for contactless payments; checking availability of equipment; and providing more detailed information about collections. Among examples of IoT use in libraries, the following content is listed: using RIFD technology for self-checkout; using floor pressure pads and beacons to track users' movements and provide them with contextual information; using wristbands as library cards, and many others. In summary, it seems that IoT technology can be used in libraries to support both back-office processes and services for users.

Overall, it seems that introducing the IoT in libraries is an imminent and inevitable prospect that brings both great prospects and challenges. Therefore, it is particularly worth immediately discussing the pros and cons of this issue in order to be prepared for the future and efficiently prevent problems in order to gain the most benefits from the development of this technology.

\section{References}

[1]. Zoril, M., Glulam, A., Lange, S. and Basis, A. From today's intranet of things to a future internet of things: a wireless-and mobility-related view. Wireless Communications, Vol. 17(2010) No. 6, pp. 44-51.

[2]. Atmore, L., I era, A. and Moabite, G. The internet of things: a survey. Computer Networks. Vol. 54(2010) No. 15, pp. 2787-2805

[3]. Ziegeldorf, J., Morton, O. and Where, K. Privacy in the Internet of Things: threats and challenges. Security and Communication Networks. Vol. 7(2014) No. 12, pp. 2728-2742.

[4]. Information on:http://libraries.pewinternet.org/2013/01/22/library-services/

[5]. Yang, G., Gang, G., Du, J., Liu, Z. and Han, H. Security threats and measures for the Internet of Things. Journal of Tsinghua University Science and Technology. Vol. 51(2011) No. 10, pp. 1335-1340.

[6]. Xia, F., Yang, L.T., Wang, L. and Vine, A. Internet of things. International Journal of Communication Systems. Vol. 25(2012) No. 9

[7]. Information on:www.researchgate.net/profile/Patrick_Guillemin/publication/267566519_Internet_of_Thing s_Strategic_Research_Roadmap/links/5486d44e0cf289302e2c3ed0.pdf

[8]. Tan, L. and Wang, N. Future internet: the internet of things. IEEE Computer Society, Advanced Computer Theory and Engineering (ICACTE), 2010 3rd International Conference, pp. V5-376-V5-380.

[9]. Shumaker, D. Who let the librarians out? Embedded librarianship and the library manager. Reference \& User Services Quarterly, Vol. 48(2009) No. 3, pp. 239-257.

[10]. Information on:www.researchgate.net/profile/Patrick_Guillemin/publication/267566519_Internet_of_Thing s_Strategic_Research_Roadmap/links/5486d44e0cf289302e2c3ed0.pdf 
[11]. Sheng, Z., Yang, S., Yu, Y., Vasilakos, A.V., McCann, J.A. and Leung, K.K. A survey on the IETF protocol suite for the internet of things: standards, challenges, and opportunities. Wireless Communications, Vol. 20(2013) No. 6, pp. 91-98.

[12]. Schmidt, B. and Schiff, M. Towards agile business processes based on the internet of things. Advanced Manufacturing and Sustainable Logistics, Springer, Berlin, Heidelberg, pp. 257-262.

[13]. Information

on:www.fastcompany.com/3040451/elasticity/the-internet-of-things-plan-to-make-libraries-and - museums-awesome

[14]. Puja, S.M. and Satyanarayana, K.V. Internet of Things and libraries. Annals of Library \& Information Studies, Vol. 62(2015) No. 3, pp. 186-190.

[15]. Prince, J.D. 3D printing: an industrial revolution. Journal of Electronic Resources in Medical Libraries, Vol. 11(2014) No. 1, pp. 39-45.

[16]. Pereira, C. et al. Sensing as a service model for smart cities supported by internet of things. Transactions on Emerging Telecommunications Technologies. Vol. 25(2014) No. 1, pp. 81-93

[17]. Pang, Z., Tina, J. and Chen, Q. "Intelligent packaging and intelligent medicine box for medication management towards the internet-of-things", IEEE Computer Society, 16th International Conference on Advanced Communication Technology (ICACT), Piscataway, NJ, pp. 352-360.

[18]. Nolan, G. Going mobile: creating a mobile presence for your library. New Library World. Vol. 114(2013) No’s 3/4, pp. 142-150.

[19]. Moville, P. and Sullener, P. Ambient fundability: libraries, serials, and the internet of things. Serials Librarian. Vol. 58(2010) No's 1/4, pp. 33-38.

[20]. Aaron, N. Mobile libraries: librarians' and students' perspectives. College \& Research Libraries. Vol. 75(2014) No. 2, pp. 202-217.

[21]. Anttiroiko, A. and Savolainen, R. Towards library 2.0: the adoption of web 2.0 technologies in public libraries. Libra. Vol. 61(2011) No. 2, pp. 87-99.

[22]. Information on: www.fastcompany.com/3040451/elasticity/the-internet-of-things-plan-to-make-libraries-andmuseums-awesome

[23]. Information on: www.ala.org/transforminglibraries/future/trends/IoT

[24]. Aric, M. and Mahmoud, K. The changing role of librarians in the digital world: adoption of Web 2.0 technologies by Pakistani librarians. The Electronic Library. Vol. 30(2012) No. 4, pp. 469-479.

[25]. Fang, X. On the construction of Wisdom Libraries in university library. Research on Library Science. Vol. 6(2014) No. 7, pp. 15-21.

[26]. Glove, J., Sabot, T. and Vanda, V. Business models for the Internet of Things environment. Procardia Economics and Finance. Vol. 15(2014), pp. 1122-1129.

[27]. Information on: www.rfidjournal.com/articles/view?12521/

[28]. Gobi, J., Bunya, R., Music, S. and Palaniswami, M... Internet of Things (Iota): a vision, architectural elements, and future directions. Future Generation Computer Systems. Vol. 29(2013) No. 7, pp. 1645-1660

[29]. Hoy, M.B... The 'Internet of Things': what it is and what it means for libraries. Medical Reference Services Quarterly. Vol. 34(2015) No. 3, pp. 353-358. 
[30]. Li, X. and Lin, A. The new directions of expanding service in colleges and universities libraries under internet of things environment. Journal of Liuzhou Vocational \& Technical College, Vol. 13(2013) No. 1, pp. 105-107. 